\title{
Motor improvement in cerebellar ataxia after integral rehabilitation
}

\author{
This article was published in the following Dove Press journal: \\ Journal of Neurorestoratology \\ 2 October 2013 \\ Number of times this article has been viewed
}

\section{Jorge L Jorge-Rodríguez' \\ Elizabeth Fernández- \\ Martínez' \\ Daymi Rodríguez Pérez' \\ Antonio Peralta-Flores ${ }^{2}$ \\ Jorge A Bergado'}

'International Center for Neurological Restoration, ${ }^{2}$ University for Sport

Science and Physical Culture,

Havana, Cuba
Correspondence: Jorge A Bergado Centro Internacional de Restauración Neurológica, Ave 25 No 15805 esq 158 Cubanacán, Playa, La Habana, Cuba I I 300 $\mathrm{Tel}+53727 \mid 6385$

Fax +53 72732420

Email bergado@neuro.ciren.cu

\begin{abstract}
Cerebellar ataxia is a complex motor impairment arising from neurologic disease. The dysfunction significantly impairs quality of movement, equilibrium, and gait. In this study, we evaluated motor function in 20 patients with acquired or degenerative ataxia undergoing rehabilitation using a program developed at the International Center for Restorative Neurology in Havana. All patients were evaluated before and 28 and 42 days after treatment using the International Cooperative Ataxia Rating Scale (ICARS) and measurement of maximal strength. Analysis of variance demonstrated a significant reduction in ICARS score, indicating reduction in the severity of ataxia. A highly significant correlation was found between change in ICARS score and increase in lower limb strength. The program developed at the International Center for Restorative Neurology in Havana for rehabilitation of ataxia was shown to be effective for ameliorating motor impairment in patients with ataxia, independent of its etiology.
\end{abstract}

Keywords: ataxia, rehabilitation, motor recovery, strength, plasticity

\section{Introduction}

Cerebellar ataxia is a common consequence of neurologic disease, with more than 400 types having been described. ${ }^{1}$ The disease leads to progressive impairment, primarily affecting posture and equilibrium, along with impaired limb movement (both superior and inferior), oculomotor control, and gait. These difficulties affect the life of the patient and that of relatives, constituting a huge economic burden..$^{2-4}$

There are at present no effective drugs available to treat ataxia. ${ }^{5,6}$ Rehabilitation is, therefore, an essential tool when aiming to recover motor function or to reduce the level of impairment. ${ }^{3,7-9}$ Several programs have been designed to rehabilitate patients with ataxia, based on neural plasticity and the adaptive abilities of the adult nervous system. ${ }^{1,8,10}$

The International Center for Neurological Restoration (CIREN) in Havana has implemented an intensive multidisciplinary program for the treatment of neurologic sequelae, including ataxia. It consists of a group of training and fitness activities under the control of different therapists and physicians aimed at reacquisition of motor abilities. ${ }^{10}$

The results of a pilot study in a small group of patients with ataxia suggested a positive impact of our restorative program on motor control. The present study was performed to confirm or refute those results in a larger group of patients who came to our institution seeking to improve their neurologic status and living conditions. 


\section{Subjects and methods}

Twenty patients diagnosed with acquired or degenerative cerebellar ataxia and treated at CIREN from September 2009 to April 2010 were included in the study. All patients were evaluated and diagnosed by a neurologic team (Table 1) and entered in the study after signing their agreement. Patients with concomitant brain lesions, terminal chronic disease, severe cognitive impairment (Mini-Mental State Examination score $<14$ ), or mental retardation were excluded, along with those who were illiterate or had clinical signs of aphasia, apraxia, agnosia, severe depression, or any other psychiatric condition precluding effective interaction with the therapist.

All patients underwent 42 days of neurorestorative treatment following the steps defined in the program, ie, general physical condition, specific physical condition, prefunctional, training and functional training (Table 2). The treatment program is based on a multifactorial, intensive, and personalized strategy. The daily schedule typically includes 5 hours of physical therapy, one hour of occupational therapy, and one hour of speech therapy, comprising 7 hours of guided activity per day. Importantly, our intention was to evaluate the efficacy of the program and that of any particular component of it.

No control group was included. One reason for this is that patients come to our institution for a limited time and pay for

Table I Description of the patient sample included in the study

\begin{tabular}{lllll}
\hline Patient & $\begin{array}{l}\text { Age } \\
\text { (years) }\end{array}$ & Sex & Etiology & Classification \\
\hline I & 21 & M & Medulloblastoma & Acquired \\
2 & 26 & F & TBI & Acquired \\
3 & 23 & M & TBI & Acquired \\
4 & 31 & M & TBI & Acquired \\
5 & 31 & M & TBI & Acquired \\
6 & 29 & M & TBI & Acquired \\
7 & 51 & M & Medulloblastoma & Acquired \\
8 & 27 & F & Hypoxia & Acquired \\
9 & 26 & M & TBI & Acquired \\
10 & 45 & F & TBI & Acquired \\
II & 24 & M & Cerebral palsy & Acquired \\
12 & 24 & M & TBI & Acquired \\
13 & 25 & M & Angioma & Acquired \\
14 & 21 & M & TBI & Acquired \\
15 & 19 & F & Friedreich's ataxia & Hereditary \\
16 & 23 & M & SCA & Hereditary \\
17 & 16 & M & Friedreich's ataxia & Hereditary \\
18 & 30 & F & Friedreich's ataxia & Hereditary \\
19 & 22 & M & Friedreich's ataxia & Hereditary \\
20 & 36 & M & SCA7 & Hereditary \\
\hline
\end{tabular}

Abbreviations: $\mathrm{TBI}$, traumatic brain injury; SCA, spinocerebellar ataxia; $\mathrm{M}$, male; $F$, female.
Table 2 Overview of the physical rehabilitation program for ataxia at the International Center for Neurological Restoration

\begin{tabular}{lll}
\hline Step & Goals & Activities \\
\hline General & Reduction of & Thermotherapy \\
physical & osteomyoarticular retractions & Therapeutic massage \\
condition & Improve muscle tone & Breathing exercises \\
& Increase respiratory capacity & Passive, active, and \\
& Increase general fitness and & resisted mobilizations \\
& working capacity & Ideomotor training \\
& & Exercises to reduce \\
& & rigidity \\
Specific & Consolidate achievements & Exercises for general \\
physical & of the previous step & Coordination exercises \\
condition & Improve coordination & Exercises with weight \\
& (proprioception, equilibrium, & Mechanotherapy \\
& rhythm, and precision) & (step simulator, static \\
& Improve posture & bicycle) \\
Increase force & \\
Prefunctional & Consolidate previous & Training of gait \\
training & achievements & Body transfers \\
& Training in static and & Static equilibrium \\
& dynamic gait patterns & Mechanotherapy \\
& Increase resistance & \\
Functional & Consolidate previous & Dynamic equilibrium \\
training & achievements & Coordination training \\
& Improve equilibrium, & (presport activities \\
& coordination, and rhythm & with balls) \\
Improve gait & Walking, trotting, and \\
& & running \\
\hline
\end{tabular}

their treatment. Another aspect to consider is that all patients included in the study had a long history of ataxia without signs of spontaneous recovery, making it plausible to consider any improvement a consequence of the treatment.

We used the International Cooperative Ataxia Rating Scale (ICARS, Table 3) to evaluate cerebellar dysfunction. The ICARS scale is useful for evaluation of severity and temporal changes in patients with ataxia. ${ }^{11,12}$ Two external evaluators (both experienced neurologists) not involved in administration of therapy applied the ICARS scale before and at two time points ( 28 and 42 days) after starting rehabilitation. The validity of the results was confirmed using the Cronbach's alpha coefficient.

A maximum strength score was also used for the lower limbs. Measurements were carried out by an external independent expert in physical therapy following the method described by Kraemer and Fry. ${ }^{11}$ After general and lower limb warm-up, external weights were applied during hip flexion, extension, abduction, and adduction, and during knee extension on the horizontal press and on the quadriceps bench. The weight was steadily increased until the patient 
Table 3 International Cooperative Ataxia Rating Scale (200I)

\begin{tabular}{|c|c|c|}
\hline Subscale & Item & Score range \\
\hline \multirow[t]{7}{*}{$\begin{array}{l}\text { Posture and } \\
\text { gait disturbances }\end{array}$} & $\begin{array}{l}\text { Walking capacities: patient's gait is observed during a } 10 \mathrm{~m} \text { walking test, including a half turn, near a wall at } \\
\text { about } 1.5 \mathrm{~m}\end{array}$ & $0-8$ \\
\hline & $\begin{array}{l}\text { Gait speed: patients who score } \mathrm{I}-3 \text { on the preceding test are observed for gait speed; those who scored } 4 \text { or } \\
\text { more on the preceding test automatically score } 4 \text { in this test }\end{array}$ & $0-4$ \\
\hline & $\begin{array}{l}\text { Standing capacities, eyes open: the patient is asked first to try to stand on one foot; if impossible, to stand } \\
\text { with feet in the tandem position; if impossible, to stand with feet together; for the natural position, the patient } \\
\text { is asked to find a comfortable standing position }\end{array}$ & $0-6$ \\
\hline & $\begin{array}{l}\text { Spread of feet in natural position without support and eyes open: the patient is asked to find a comfortable } \\
\text { standing position, and the distance between the medial malleoli is then measured }\end{array}$ & $0-4$ \\
\hline & Body sways with feet together, eyes open & $0-4$ \\
\hline & Body sways with feet together, eyes closed & $0-4$ \\
\hline & Quality of sitting position (thighs together, on a hard surface, arms folded) & $0-4$ \\
\hline Total category & & 34 \\
\hline \multirow[t]{23}{*}{ Kinetic functions } & Knee-tibia test (decomposition of movement and intention tremor): the test is performed in the supine & $0-4$ \\
\hline & position so that visual control is possible; the patient is requested to raise one leg and place the heel on the & \\
\hline & opposite knee, and then slide the heel down the anterior tibial surface toward the ankle; on reaching the & \\
\hline & ankle joint, the leg is raised again to a height of approximately $40 \mathrm{~cm}$ and the action is repeated; at least three & \\
\hline & movements of each limb must be performed for proper assessment & \\
\hline & Action tremor in the heel-to-knee test: during the same test as the preceding one, the action tremor of the & $0-4$ \\
\hline & heel on the knee is observed specifically while the patient holds the heel on the knee for a few seconds before & \\
\hline & sliding it down the anterior tibial surface; visual control is required & \\
\hline & Finger-to-nose test (decomposition and dysmetria): the subject sits in a chair; the hand is resting on the knee & $0-4$ \\
\hline & before the beginning of the movement; visual control is required; three movements of each limb must be & \\
\hline & performed for proper assessment & \\
\hline & Finger-to-nose test (intention tremor of the finger): the studied tremor is that appearing during the ballistic & $0-4$ \\
\hline & phase of the movement; the patient is sitting comfortably with the hand resting on his/her thigh; visual control & \\
\hline & is required; three movements of each limb must be performed for proper assessment & \\
\hline & Finger-finger test (action tremor and/or instability): the seated patient is asked to maintain his/her index & $0-4$ \\
\hline & $\begin{array}{l}\text { fingers pointing at each other for about } 10 \text { seconds, at a distance of } \mathrm{I} \mathrm{cm} \text {, at the level of the thorax, under } \\
\text { visual control }\end{array}$ & \\
\hline & Pronation-supination alternating movements: the subject, comfortably seated on a chair, is asked to raise & $0-4$ \\
\hline & his/her forearm vertically and to make alternating pronating and supinating movements of the hand; each & \\
\hline & hand is moved and assessed separately & \\
\hline & Drawing of the Archimedes spiral on a predrawn pattern: the subject is comfortably settled in front of a & $0-4$ \\
\hline & table, with a sheet of paper fixed to avoid artifacts; the subject is asked to perform the task without timing & \\
\hline & requirements; the same conditions of examination must be used at each examination (eg, same table, same & \\
\hline & pen); the dominant hand is examined & \\
\hline Total category & & 52 \\
\hline Speech & Dysarthria (fluency of speech): the patient is asked to repeat a standard sentence several times, always the & \\
\hline \multirow[t]{2}{*}{ disorders } & same, eg, "A mischievous spectacle in Czechoslovakia" & \\
\hline & Dysarthria (clarity of speech) & \\
\hline Total category & & 8 \\
\hline Oculomotor & Gaze-evoked nystagmus: the subject is asked to look laterally at the finger of the examiner; the movements & \\
\hline \multirow[t]{6}{*}{ disorders } & assessed are mainly horizontal, but they may be oblique, rotatory, or vertical & \\
\hline & Abnormalities of ocular pursuit: the subject is asked to follow a slow lateral movement performed by the & \\
\hline & finger of the examiner & \\
\hline & Dysmetria of the saccade: two index fingers of the examiner are placed in each temporal visual field of the & \\
\hline & patient, whose eyes are in the primary position; the patient is then asked to look laterally at the finger, & \\
\hline & on the right and on the left; the average overshoot or undershoot of the two sides is then estimated & \\
\hline Total category & & 6 \\
\hline Total scale & & 100 \\
\hline
\end{tabular}

was unable to perform the task. The final score was the sum of all weights reached for each muscle measured.

Statistical data processing was performed by analysis of variance and regression analysis. $P<0.05$ was considered to be statistically significant.

\section{Results}

\section{Significant changes on ICARS scale}

Table 4 summarizes the scores on the ICARS scale for each of the time points of evaluation (before treatment, and 28 days and 42 days after initiation of rehabilitation). Repeated-measures 
Table 4 ICARS score before and after treatment

\begin{tabular}{|c|c|c|c|}
\hline $\begin{array}{l}\text { Scale } \\
\text { (maximum } \\
\text { score) }\end{array}$ & $\begin{array}{l}\text { Before } \\
\text { treatment } \\
\text { Mean } \pm \text { SEM } \\
\text { (CI) }\end{array}$ & $\begin{array}{l}\text { Mean } \pm \text { SEM } \\
(\mathrm{Cl})\end{array}$ & $\begin{array}{l}\text { Mean } \pm \text { SEM } \\
\text { (CI) }\end{array}$ \\
\hline $\begin{array}{l}\text { Posture } \\
\text { and gait } \\
\text { disturbances (34) }\end{array}$ & $\begin{array}{l}22.4 \pm 1.59 \\
(19.27-25.52)\end{array}$ & $\begin{array}{l}19.35 \pm 1.73 \\
(15.95-22.74)^{*}\end{array}$ & $\begin{array}{l}\mid 8.8 \pm 1.91 \\
(15.06-22.53)^{*}\end{array}$ \\
\hline $\begin{array}{l}\text { Kinetic } \\
\text { function (52) }\end{array}$ & $\begin{array}{l}18.8 \pm 2.03 \\
(14.80-22.79)\end{array}$ & $\begin{array}{l}\mid 4.75 \pm 1.87 \\
(|1.07-| 8.42)^{*}\end{array}$ & $\begin{array}{l}|3.15 \pm| .4 \mid \\
(|0.39-| 5.90) *\end{array}$ \\
\hline $\begin{array}{l}\text { Speech } \\
\text { disorders (8) }\end{array}$ & $\begin{array}{l}2.35 \pm 0.27 \\
(1.81-2.88)\end{array}$ & $\begin{array}{l}2 \pm 0.21 \\
(1.59-2.40)\end{array}$ & $\begin{array}{l}1.9 \pm 0.20 \\
(1.50-2.29)^{*}\end{array}$ \\
\hline $\begin{array}{l}\text { Oculomotor } \\
\text { disorders (6) }\end{array}$ & $\begin{array}{l}1.85 \pm 0.35 \\
(1.16-2.53)\end{array}$ & $\begin{array}{l}1.6 \pm 0.31 \\
(0.99-2.20)\end{array}$ & $\begin{array}{l}1.6 \pm 0.30 \\
(1.01-2.19)\end{array}$ \\
\hline $\begin{array}{l}\text { Total ICARS } \\
\text { score }(100)\end{array}$ & $\begin{array}{l}45.4 \pm 3.43 \\
(38.66-52.14)\end{array}$ & $\begin{array}{l}37.7 \pm 3.16 \\
(31.50-43.89)^{*}\end{array}$ & $\begin{array}{l}35.45 \pm 2.93 \\
(29.70-41.19)^{*}\end{array}$ \\
\hline
\end{tabular}

Notes: $* P<0.05$ Tukey's (honest significant difference) test (horizontal comparisons); alpha $=0.05$

Abbreviations: $\mathrm{Cl}$, confidence interval; ICARS, International Cooperative Ataxia Rating Scale; SEM, standard error of the mean.

analysis of variance confirmed a significant decrease in total ICARS score at 28 and 42 days $\left(F_{2,36}=16.9977, P<0.05\right.$, see Figure 1), indicating a reduction in the severity of ataxia. Tukey's post hoc test confirmed significant differences between the initial score and both post training evaluations, but not between the post training scores.

\section{Most important improvements}

\section{seen in posture, gait, and kinetic} function subscales

A detailed analysis, considering each subscale of the ICARS scale, allowed more precise evaluation of the results. Repeated-measures analysis of variance demonstrated that treatment led to a significant reduction in the subscale measuring posture and gait $\left(F_{2,38}=7.9344, P<0.05\right.$, see Figure 2). Tukey's post hoc test confirmed significant differences between pretreatment evaluation and measurements during and after treatment, but no differences between the two post training scores. Items showing the most improvement were those related to posture and equilibrium, ie, body oscillations with eyes closed or opened and the quality of the sitting position, but no improvements in gait speed were noted.

The subscale for kinetic function also showed significant improvement (repeated-measures analysis of variance, $F_{2,38}=15.66580, P<0.05$, see Figure 3 ). Tukey's post hoc test confirmed significant differences between the before and after treatment evaluations, but not between the two post training scores. Action tremor showed a significant reduction, but dysmetria in the upper limbs showed no improvement.

\section{Average ICARS score}

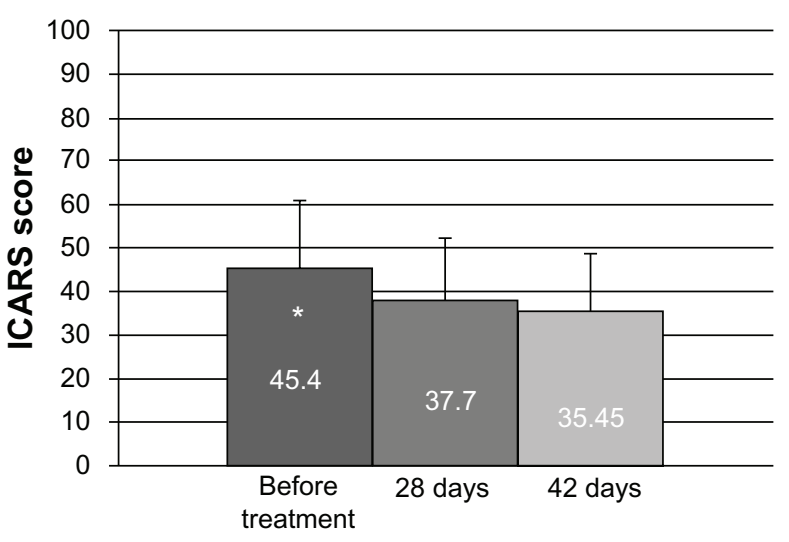

Figure I Modifications in ICARS score after rehabilitation treatment.

Notes: Mean \pm standard error of the mean (*significant difference, $P<0.05$ Tukey's test)

Abbreviation: ICARS, International Cooperative Ataxia Rating Scale.

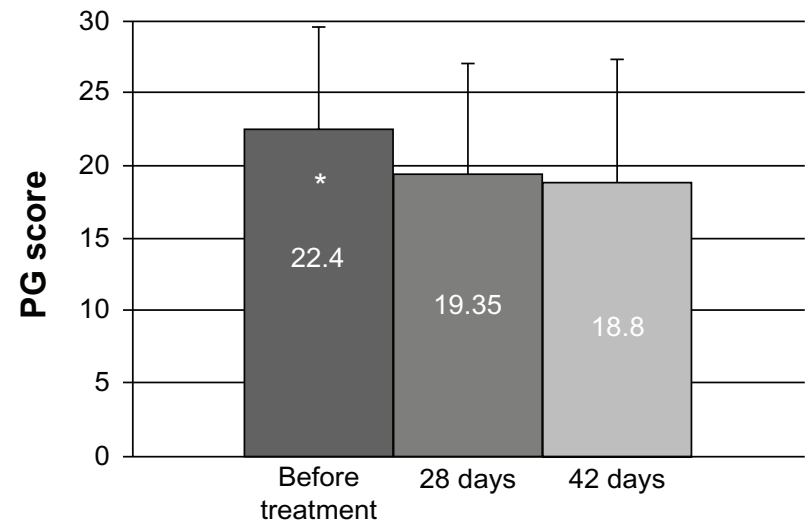

Figure 2 Modifications in the subscale for PG after rehabilitation treatment. Notes: Mean \pm standard error of the mean (*significant difference, $P<0.05$, Tukey's test).

Abbreviation: PG, posture and gait.

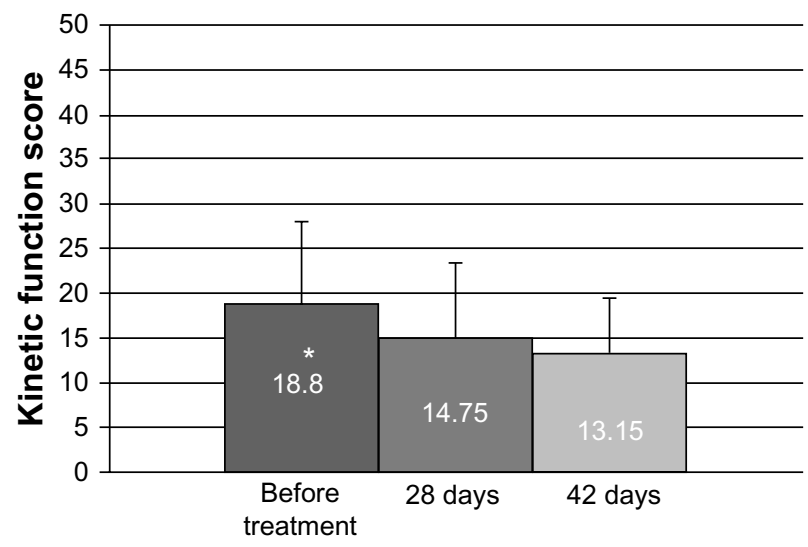

Figure 3 Modifications in the subscale for Kinetic functions after rehabilitation treatment.

Notes: Mean \pm standard error of the mean (*significant difference, $P<0.05$, Tukey's test).

Abbreviation: MF, motor function. 
Rehabilitation also brought about significant amelioration of language impairment, as shown by a global reduction in scores on this subscale (repeated-measures analysis of variance, $F_{2,38}=3.6062$ ), but no significant changes were observed on the oculomotor scale (repeated-measures analysis of variance, $F_{2,38}=3.51852$ ).

\section{Correlation analysis}

Analyzing the relationship between improvement and other independent variables, no significant relationships were found between global ICARS improvement (final value/ initial value percent) and the etiology of ataxia (hereditary or acquired, one-way analysis of variance, $F_{1,18}=0.0217$ ). Regression analysis showed that the initial level of cognitive impairment $\left(R^{2}=0.13174881\right)$, age $\left(R^{2}=0.02792980\right)$, and time of development of ataxia $\left(R^{2}=0.01929383\right)$ had no influence on the outcome of rehabilitation.

On the other hand, one-way analysis of variance showed that treatment significantly modified maximal strength in the lower limbs $\left(F_{2,38}=38.40207, P<0.05\right.$, see Figure 4$)$. These results were confirmed by the highly significant relationship found on regression analysis between the change in ICARS score and maximal strength $\left(R^{2}=0.99919140\right)$.

In summary, this neurorestorative program brought about improvement in global scores for ataxia in our study patients, which appeared to be independent of the etiology of ataxia. The most important improvements were observed in posture, equilibrium, intention tremor, language, and muscle strength in the lower limbs, while gait, dysmetria, and oculomotor control showed no relevant amelioration.

\section{Discussion}

Our results confirm that neurorehabilitation can be a useful tool for treating motor impairment caused by cerebellar ataxia., ${ }^{3,10,14,15}$

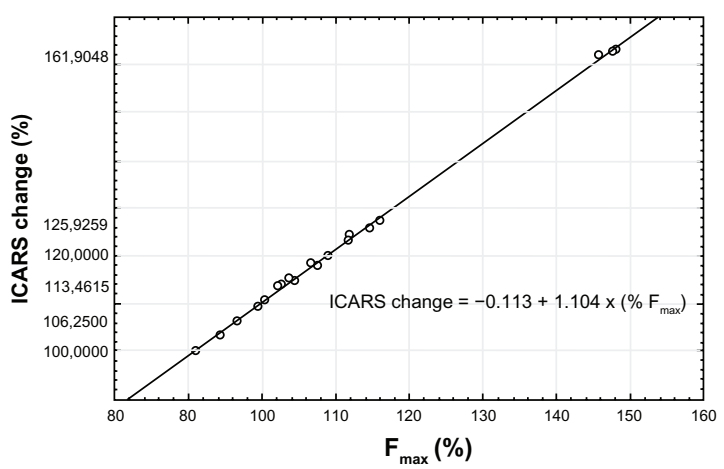

Figure 4 Scatter plot and regression curve for the relationship between change in ICARS score after treatment (\% ICARS change) and change in maximal force $\left(\% \mathrm{~F}_{\max }\right)$. Abbreviation: ICARS, International Cooperative Ataxia Rating Scale.
However, these results are difficult to compare with those reported by others because of differences in conception, duration, intensity, patient selection, and outcome measures used, as well as use of combined therapies, among other factors. ${ }^{14-20}$

The beneficial effect of the program used in this study is reflected in a significant reduction of the global ICARS score. The intensive rehabilitation strategy used in our program induced significant changes after 28 days of treatment, but extending it for 15 additional days did not result in further significant improvement. Short-term improvement after rehabilitation in patients with ataxia has been demonstrated in other studies, and although the benefits decay with time, gains can last for long periods. ${ }^{21,22}$

All subscales of the ICARS, except for oculomotor control, improved after treatment, while some items showed no significant change. The posture and gait section showed improvement in the posture and equilibrium items, but not for gait speed. On the motor function scale, tremor was improved but not dysmetria.

Our study shows a strong positive relationship between increase in strength and improvement in motor control, in agreement with previous reports. ${ }^{23,24}$ Increased strength in the lower limbs would certainly contribute to increased stability and postural control, as suggested by the significant improvement in the posture and gait subscale.

Gait is a complex motor behavior usually learned during early childhood. ${ }^{25}$ Reacquisition of gait in older age is extremely complex and difficult. ${ }^{26}$ Effective treatment of gait disturbance requires development of compensation, strength, and equilibrium, all of which are affected by ataxia and the reduction in motor activity caused by the disease. According to the literature, modest improvements in gait have been obtained only after long-term rehabilitation ( 6 months or longer), ${ }^{25,27}$ far beyond the time interval tested in the present study. Language alterations are well documented in ataxia, but the effects of rehabilitation have been discrete ${ }^{28}$ and are consistent with our results.

Neurorehabilitation ameliorates symptoms of ataxia, independent of its etiology, ${ }^{9}$ although less favorable results have been reported for ataxia attributable to degenerative disease, probably because of the progressive nature of the condition..$^{21,24}$ It must be taken into consideration in our study that the number of patients with hereditary ataxia represented only about one third of the total patient group, which may have introduced some bias.

\section{Conclusion}

Our results confirm that intense neurorehabilitation is useful for treating and improving motor ability in patients suffering 
from ataxia. Although the results point to the major contribution being a gain in muscle strength, intensive training is also likely to assist in relearning of motor abilities, and could also improve sensory feedback, favoring acquisition of motor skills. ${ }^{29}$ In this regard, a role for neural plasticity mechanisms, ${ }^{30-32}$ which have been well studied and characterized in the cerebellum, ${ }^{26,33}$ can also be invoked. The specific role of cerebellar plasticity in motor learning and motor control in humans is still being researched.

\section{Disclosure}

The authors report no conflicts of interest in this work.

\section{References}

1. Annunciato NF, Neves de Oliveira C. La influencia de la terapia sobre los procesos plásticos del sistema nervioso: teoría e investigación. Rev Fisioter. 2008;6:33-39. Spanish.

2. Bergado J, Almaguer W. Mecanismos celulares de la neuroplasticidad. Rev Neurol. 2000;31:1074-1095. Spanish.

3. Cernak A, Stevens V, Price R, Shumway-Cook A. Locomotor training using body-weight support on a treadmill in conjunction with ongoing physical therapy in a child with severe cerebellar ataxia. Phys Ther. 2008;88:88-97.

4. Ferrarin M, Gironi M, Mendozzi L, Nemni R, Mazzoleni P, Rabuffetti M. Procedure for the quantitative evaluation of motor disturbances in cerebellar ataxic patients. Med Biol Eng Comput. 2005;43:349-356.

5. Freund JE, Stetts DM. Use of trunk stabilization and locomotor training in an adult with cerebellar ataxia: a single system design. Physiother Theory Pract. 2010;26:447-458.

6. Gazulla J. Actualización en neuroquímica y terapeútica farmacológica de las ataxias cerebelosas. Rev Neurol. 2007;45:31-41. Spanish.

7. Gómez L. Bases neurales de la recuperación motora en las lesiones cerebrales. Rev Méx Neurosci. 2001;2:216-221. Spanish.

8. Hansel C, Linden DJ, D'Angelo E. Beyond parallel fiber LTD: the diversity of synaptic and non-synaptic plasticity in the cerebellum. Nat Neurosci. 2001;4:467-475.

9. Harris-Love MO, Lohman K, Paul S, Benson K. Rehabilitation management of Friedreich ataxia: lower extremity force control variability and gait. Neurorehabil Neural Repair. 2004;18:117-124.

10. Hernando A, Useros A. Métodos fisioterapeúticos aplicados a pacientes adultos condaño cerebral adquirido. Biociencias. 2008;6:3-23. Spanish.

11. Kraemer WJ, Fry AC. Strength testing: development and evaluation. In: Maud PJ, editor. Physiological Assessment of Human Fitness. Champaign, IL: Human Kinetics; 1995.

12. Ilg W, Brotz D, Burkard S, Giese MA, Schols L, Synofzik M. Long-term effects of coordinative training in degenerative cerebellar disease. Mov Disord. 2010;25:2239-2246.

13. Ilg W, Synofzik M, Brotz D, Burkard S, Giese MA, Schols L. Intensive coordinative training improves motor performance in degenerative cerebellar disease. Neurology. 2009;73:1823-1830.

14. Kelly PJ, Stein J, Shafqat S, et al. Functional recovery after rehabilitation for cerebellar stroke. Stroke. 2001;32:530-534.

Journal of Neurorestoratology

\section{Publish your work in this journal}

The Journal of Neurorestoratology is an international, peer-reviewed, open access online journal publishing original research and review articles on the subject of Neurorestoratology. To provide complete coverage of this revolutionary field the Journal of Neurorestoratology will report on relevant experimental research, technological advances, and

Submit your manuscript here: http://www.dovepress.com/journal-of-neurorestoratology-journal
15. López-Bastida J, Perestelo-Pérez L, Montón-Alvarez F, SerranoAguilar P. Social economic costs and health- related quality of life in patients with degenerative cerebellar ataxia in Spain. Mov Disord. 2008;23:212-217.

16. Marsden J, Harris C. Cerebellar ataxia: pathophysiology and rehabilitation. Clin Rehabil. 2011;25:195-216.

17. Martin C, Tan D, Bragge P, Bialocerkowski A. Effectiveness of physiotherapy for adults with cerebellar dysfunction: a systematic review. Clin Rehabil. 2009;23:15-26.

18. Hatakenaka M, Miyai I, Mihara M, Yagura H, Hattori N. Impaired motor learning by a pursuit rotor test reduces functional outcomes during rehabilitation poststroke ataxia. Neurorehabil Neural Repair. 2012;26:293-300.

19. Mihara M, Miyai I, Hatakenaka M, Kubota K, Sakoda S. Sustained prefrontal activation during ataxic gait: a compensatory mechanism for ataxic stroke? Neuroimage. 2007;37:1338-1345.

20. Miyai I. Challenge of neurorehabilitation for cerebellar degenerative diseases. Cerebellum. 2012;11:436-437.

21. Miyai I, Ito M, Hattori N, et al. Cerebellar ataxia rehabilitation trial in degenerative cerebellar diseases. Neurorehabil Neural Repair. 2012;26: $515-522$.

22. Morton S, Bastian A. Can rehabilitation help ataxia? Neurology. 2009;73:1818-1819.

23. Morton S, Tseng Y, Zackowski K, Daline J, Bastian A. Longitudinal tracking of gait and balance impairments in cerebellar disease. Mov Disord. 2010;25:1944-1952.

24. Morton SM, Bastian AJ. Mechanisms of cerebellar gait ataxia. Cerebellum. 2007;6:79-86.

25. Perez I, Fernandez JA, Martinez E, Ochoa R, Velazquez MG. Effects of a physical training program on quantitative neurological indices in mild stage type 2 spinocerebellar ataxia patients. Rev Neurol. 2004;39:907-910. Spanish.

26. Rinaldo L, Hansel C. Ataxias and cerebellar dysfunction: involvement of synaptic deficits? Funct Neurol. 2010;25:135-139.

27. Rodríguez J, Velázquez L, Sánchez G, et al. Evaluación de la restauración neurológica en pacientes con ataxia SCA2 cubana. Plast Rest Neurol. 2008;7:13-17.

28. Schalow G. Improvement after cerebellar injury achieved by coordination dynamics therapy. Electromyog Clin Neurophysiol. 2006;46: 433-439.

29. Sentmanat A. Influencia de la Neurorrehabilitación multifactorial intensiva para la recuperación de las capacidades coordinativas en pacientes portadores de ataxia cerebelosa causada por accidente cerebro vascular o esclerosis múltiple. Rev Dep. 2003;3:7-8. Spanish.

30. Serrano P, Montón F, Trujillo M, Carrillo R, González A. Efectividad y seguridad de las alternativas terapéuticas frente a las ataxias degenerativas. Colección: Informes, estudios e investigación. Available from: http://ww.gobiernodecanarias.org/sanidad/sescs/http://aunets.isciii.es/, 2006/18. Accessed June 2009. Spanish.

31. Stephan MA, Krattinger S, Pasquier J, et al. Effect of long-term climbing training on cerebellar ataxia: a case series. Rehabil Res Pract. 2011;2011:525-579.

32. Trujillo MM, Serrano P, Monton F, Carrillo R. Effectiveness and safety of treatments for degenerative ataxias: a systematic review. Mov Disord. 2009;24:1111-1124.

33. Tyrone E, Atkinson J, Marshall J, Woll B. The effects of cerebellar ataxia on sign language production: a case study. Neurocase. 2009;15:419-426.

clinical achievements. The manuscript management system is completely online and includes a very quick and fair peer-review system, which is all easy to use. Visit http://www.dovepress.com/testimonials.php to read real quotes from published authors. 